\title{
LOS DISGURSOS DEL BLUES EN CROSSROADS, DE WALTER HILL
}

\author{
Ferrán Riesgo \\ Universidad de Alicante
}

\section{CAMINO AL DELTA}

De todo lo que se ha dicho o escrito acerca del virtuoso del blues Robert Johnson (19111938), muy poco es demostrablemente cierto. Walter Hill eligió comenzar Crossroads (Cruce de caminos, 1986) con un hecho improbable y otro indiscutiblemente real: el joven Robert esperando al diablo en un cruce de caminos del Sur, y el mismo Robert un tiempo después, grabando el célebre Cross Road's Blues y plantando así los esquejes de un mito que tenía medio siglo por delante para florecer.

Johnson es ahora la figura más conocida del llamado blues "rural" o "del Delta", la forma de blues comúnmente considerada más primitiva o "pura". En la red de misterios, leyendas y anécdotas que lo envuelve toma forma acabada el arquetipo del bluesman: vagabundo, bebedor, mujeriego, nostálgico, sufrido, y oscuramente relacionado con el Diablo y los cultos vudú; la leyenda más célebre es que su pericia musical la había cambiado por su alma en un cruce de caminos, en un pacto con el diablo'. Este es el hilo conductor soterrado de todo el film, y el leitmotiv del personaje de Willie Brown (Joe Seneca), compañero ocasional de Johnson en los primeros años treinta, que vive siempre torturado por el recuerdo y acicateado por el miedo. Era el punto de partida ideal para la película de Hill.

El argumento es sencillo. El joven Eugene (Ralph Macchio) localiza a Willie Brown, antiguo compañero de Johnson, en un geriátrico de Harlem, y, convencido de que Brown es el único conocedor de una supuestamente perdida canción número treinta de Johnson, lo ayuda a fugarse del hospital y regresar al Sur, a condición de que le enseñe la canción. Crossroads deviene así una especie de bildungsroman o viaje de formación para el joven, que desea, por encima de todas las cosas, "ser un bluesman", algo que ya está medio convencido de haber logrado. Frances (Jami Gertz), una adolescente pobre que también viaja a dedo por el Delta, será, por su parte, la iniciación del joven en el sexo y el dolor del abandono.

Sin embargo, ¿qué es, exactamente, un bluesman? ¿Existe ese conglomerado de tópi-

1 Sobre la vida de Johnson, v. Hunt, 1992; Schroeder, 2004; y Wald: 2006. Sobre la dimensión mítica de Johnson, Rothenbuhler: 2007 y Schroeder. Asimismo letras de Johnson como "Me and the Devil Blues", "Hellhound on my trail" o "Crossroads Blues". 
cos e historias que es blues del Delta? De pie sobre el asfalto de la Ruta 61, Brown asegura: "you go down this road, and you run right smack-dab in the heart of where it all started". La película de Hill está llena de referencias, pero, ¿cuál es la raíz de todo ello, una verdadera entidad cultural fuerte o una mera suma de tópicos modernos y ficciones atractivas? ¿Cuál es el discurso del blues, y cuál el discurso sobre el blues, en Crossroads? Las respuestas a estas preguntas pasan, primero, por dilucidar, al menos de modo general, en qué consiste realmente esa cultura del blues, para luego tratar de comprender cuál es el modelo, el arquetipo de bluesman que se propone a través del viaje iniciático de Eugene.

La primera cuestión a resolver sería si realmente puede localizarse, geográfica y cronológicamente, la cuna del blues. Gerhard Kubik la sitúa entre la costa sureste de Estados Unidos y el estado de Texas: el Delta, que no es propiamente el delta geográfico al sur de Nueva Orleans, sino una región más amplia de influencia musical que comprende a los estados de Mississippi, Alabama, Arkansas, y parte de Tennessee y Louisiana (Kubik, 1999: 82-83). En cuanto a la música, el blues rural sería "una música folclórica, puesto que se perpetúa a través de la tradición oral. Las canciones se transmiten de boca en boca, a la vez que su ejecución se aprende viendo y escuchando a otros intérpretes" (Tirro, 2007: 78). Las raíces africanas, tanto telúricas como sonoras, son fundamentales también para todos los estudiosos. Se trata, pues, del producto genuino de un grupo humano determinado, "cuyos valores y perspectivas refleja. Cuando el grupo se transforma, la música también cambia" (id.). La concepción que podamos concretar sobre esta deberá renunciar a la exactitud ${ }^{2}$.

Sus características son diversas y hacen referencia a varios aspectos del complejo músico-conceptual del blues. Kubik habla, por ejemplo, de un predominio de cantantes solistas, con letras en primera persona, del gusto por los melismas en las zonas del Delta y Texas, o la preferencia por tempos lentos y atresillados.

La progresiva popularización del blues trajo consigo, inevitablemente, una simplificación de su universo conceptual, mediada por la industria del ocio pero ya anticipada desde las primeras grabaciones y los race records de los que habla Herzhaft ${ }^{3}$. Sus propios mitos y leyendas se fueron diluyendo en la cultura global, y tras los renacimientos de los años cuarenta y sesenta, el blues ya había evolucionado mucho como constructo cultural, y se había diversificado como discurso musical: una cosa era el blues que hacían las bandas eléctricas de Chicago, Nueva York o Memphis, con una masiva participación de músicos blancos y múltiples influencias estilísticas exógenas, y otra muy distinta ese vago constructo de leyendas y clichés en que se había diluido el viejo blues del Delta.

2 "Rural blues in the Deep South is not a completely homogeneous tradition. Enough time has elapsed since pre-blues traditions crystallized into something toward the end of the nineteenth century that could be called "blues" to allow for early processes of divergence analogous to how a language splits into dialects, and subsequent processes of convergence, i.e. mutual influences and borrowings among the formerly divergent styles" (Kubik, 1999: 82). También Ottenheimer: 1979, y Switzler: 2001.

3 La primera grabación discográfica documentada surgió en 1920 cuando la cantante negra Mamie Smith se hallaba en Nueva York y fue requerida por Fred Hager (Okeh) para sustituir a otra cantante que no se presentó en el estudio. Smith grabó nueve canciones, entre ellas el hit de la época "Crazy Blues", y así comenzó el interés de los ejecutivos discográficos por la música negra del sur. Sellos como Vocalion -filial de Columbia-, Paramount o la misma Okeh quisieron abrir un mercado y etiquetarlo de modo llamativo pero "respetuoso": buscando evitar términos cono "Negro" o "black", dieron con la poco aséptica alternativa de los "race records", "grabaciones de raza", y lo desarrollaron durante los años 20 y 30 . V. Herzhaft, pp. 18 y ss. 
Tomemos el caso de Legba como ejemplo. Nombre sagrado de raigambre africana que en muchas leyendas contemporáneas y en el film se considera un equivalente del diablo. Siempre anunciado por su mediador, Scratch, que es quien firma los pactos con Johnson y Brown, es el negro viejo de amenazadora dentadura que aparece al final en el cruce y trata de agenciarse también el alma joven de Eugene. Kubik ha revisado los orígenes africanos de la figura, y explica que en la tradición africana Legba es un ídolo de las etnias Fo y Yoruba. Allí carece de connotaciones negativas y es un protector relacionado con los oráculos. La negativización de la figura de Legba puede proceder seguramente de su paso al mundo occidental, pues sabemos que estas deidades fueron perseguidas en África por los misioneros cristianos del periodo colonial, y también después en el Nuevo Mundo. La inserción de esta deidad entre las fuerzas malignas es tardía, y una visión sesgada de su papel en los cultos negroamericanos, pues aunque Legba es mencionado en las tradiciones y los blues de principios del XX, lo es como mediador y oráculo, no como un epígono de Satán: Johnson nunca utiliza su nombre en este sentido.

En las supersticiones de las etnias africanas sí hay, sin embargo, algunos formantes mitológicos que pueden servir como base para la reformulación en la tradición blues americana:

In Africa the idea that a musician makes a pact with a dangerous spiritual being in return for phenomenal musical powers is well documented. It is even thought generally that no one can develop extraordinary skills or attain fame without some "medicine" or secret liaison with the supernatural (Kubik, 1999: 24).

En cualquier caso, y aunque las palabras de Kubik remitan inevitablemente al mito de Johnson, la figura de Legba ejemplifica cómo mitologías contemporáneas como la que nos ocupa están hechas, a menudo, a partir de malas lecturas o mezclas indiscrimadas de una tradición anterior. La pregunta es: ¿hasta qué punto es este el caso de Crossroads?

La película aparece en una época en que el imaginario del blues está bien lejos de esa presunta "verdad cultural" que se busca en el concepto del Delta. Es llamativo que a nivel social Herzhaft relacione el descenso de interés de la población negra por el blues con la suave mejora o posibilidad de mejora de su situación social: "la segregación, generadora esencial del blues, estaba en vías de desaparición y, como consecuencia de ello, el blues dejaba de ser la forma musical preferida de los negros" (2003: 20). El soul (James Brown, Otis Redding...) toma el relevo. Ya en los sesenta, Leroi Jones había leído en la misma clave las evoluciones del estilo, desde una perspectiva de raza en su caso.

The primitive blues was still very much vocal music; the singers relied on the unpredictability and mobility of the human voice for their imaginative catalysts. But the growing use of European instruments [...]. When Negroes began to master more and more "European" instruments and began to think musically in terms of their timbres, as opposed to, or in conjunction with, the voice, blues began to change, and the era of jazz was at hand (Jones, 1963: 70).

Herzhaft reconoce que la popularización del blues es "una espada de doble filo": el Delta es ahora un destino para aficionados al blues, en el mejor de los casos, o sencillamente pasto de turistas que "se hacen fotografiar depositando una armónica en la tumba de Sonny 
Boy Williamson o cosechan algodón en la plantación donde nació Muddy Waters (en esta excursión la agencia de viajes incluye la comida)" (2003: 22).

¿Sucede lo mismo con los productos culturales derivados del universo blues? No los discos que se reeditan, sino películas como Crossroads. Herzhaft se pregunta, con fingida sorpresa, si "no es cierto que el blues de hoy posee más intérpretes de un pasado glorioso que verdaderos innovadores" (íd.). Su respuesta es otra pregunta: ¿existe alguna alternativa?

\section{EL ARQUETIPO DEL BLUESMAN}

El viaje al Delta en busca de la canción es un viaje iniciático en pos de la obsesión de Eugene: convertirse en un bluesman. Es esta una de esas figuras tempranamente míticas que ha producido América, un arquetipo similar al del cowboy o el gaucho argentino: son todos seres solitarios y vagabundos que nacen en la realidad sin precedentes del Nuevo Mundo, y que, ya desaparecidos como figura real, han pasado a los imaginarios colectivos, representando casi siempre modelos fuertemente identitarios para las comunidades que los atesoran.

En cuanto al bluesman, tomando a Robert Johnson como caso ejemplar, se verá que aglutina varios de los requisitos de una figura mítica. Muerto en 1938, seguramente asesinado, su vida contiene atractivas dosis de misterio, drama y aventura. Se desconoce la ubicación de su tumba y las circunstancias exactas de su muerte, solo se conservan tres fotografías de él, y ni siquiera se ha podido hallar su partida de nacimiento. Como todos los mitos, es más relevante por la Verdad que pueda encarnar que por las verdades factuales sobre su vida ${ }^{4}$.

En Crossroads hallamos dos relaciones jerárquicas simultáneas, una más diáfana que la otra. Brown hace las veces de mentor y modelo para Eugene, quien tiene a su vez su propio imaginario de mitos del blues como modelo global; el fantasma de Johnson opera como modelo de Brown, quien se debate siempre entre su condición de igual de Johnson y el miedo a seguir su destino. En su empeño por alcanzar la altura artística y el bagaje vital de sus héroes, el joven Eugene, a través de sus decisiones, no sólo logra enfilar el camino hacia la grandeza de sus ídolos, sino que redime a Willie Brown de los errores del pasado: arroja luz sobre el lado sombrío del arquetipo.

Es posible distinguir en la película siete experiencias iniciáticas que el bluesman debe completar antes de poder considerarse como tal, sietes rasgos definitorios de importancia desigual y cuestionable. El primero es enunciado indirectamente cuando Brown cuenta a Eugene, en el autobús a Memphis -de la línea Greyhound ${ }^{5}$-, que lo encarcelaron por asesinato, un asesinato "justo", eso sí: el bluesman es violento, y puede tomarse la justicia por su mano. Eugene no completará este rito nunca, y aunque Brown ponga un arma en sus manos más adelante, lo único que logra el joven al sacarla en un bar es iniciar una pelea y perder la pistola.

El segundo de los ritos está relacionado con el tópico del bluesman como vagabundo: En Memphis se quedan sin dinero, y para llegar al Delta viajan en el remolque de una camioneta de pollos, hacen autoestop, duermen en graneros... "Welcome to Blues Ville, son", se

4 V. Rothenbuhler: 2007, Schroeder: 2004, y Wenders: 2003.

5 En los tiempos de las primeras grabaciones, a menudo todo lo que los productores de Nueva York o Chicago pagaban a los chicos negros del Delta era un billete de tren o de la Greyhound, de ida y vuelta. (Herzhaft, 2003: 20). V. también Robert Johnson, en "Me and the Devil Blues": You may bury my body, ooh, down by the highway side, / so my old evil spirit, can catch a Greyhound bus and ride". 
burla Brown; "this is the real thing, this ain't no book". Eugene, como nosotros, ha leído sobre la vida de los bluesmen en libros y periódicos, pero naturalmente el auténtico bluesman es iletrado; los libros de Eugene son "Folklore shit". El tercer requisito también pertenece a la categoría de los falsos: al pisar el suelo de Mississippi, Brown tira su corbata y la cambia por una de lazo. "This is what a bluesman wears in this state", gruñe el mentor.

El cuarto rito es crucial, uno de los rasgos definitorios de Johnson: se trata de la relación con lo impío, lo arcano, del rito del pacto con el diablo. Eugene lo toma a la ligera y en un enfado sugiere, sarcástico, que tal vez debería hacer como Brown y acudir al cruce a canjear su alma por pericia musical: el viejo lo abofetea y le prohíbe volver a hablar del tema. La quinta experiencia fundamental del bluesman, por otra parte, remite el problema de la raza. Como ha quedado patente antes, el blues auténtico es cosa de negros, ya desde los race records de 1920-1930, ya desde los tiempos de África (v. Kubik: 1999; Scorsese: 2003; y Wenders: 2003). El malvado Lloyd, el dueño del bar que luego tratará de abusar de Frances — Hill lo dibuja como un ser absolutamente mezquino- los expulsa del aparcamiento del local, donde tocan para un grupo reducido de gente, e insulta gravemente a Brown: "and you can tell that old mud duck to get his ass off my property". El corolario de Brown: "Well, now you're starting to learn some deep blues".

El sexto requisito es la experiencia del desamor, el conflicto con la mujer; otro tema recurrente en las letras de Johnson. Tras haber pasado algunas noches con Eugene, Frances se marcha al amanecer, sin avisar, y el chico, fugazmente devastado, se sienta a tocar ante Brown. En este momento alcanza, virtualmente, la condición de bluesman, y su figura se funde con la sombra del mito. El viejo le dedica estas palabras, con los ojos vidriosos: "lots of towns, lots of songs, lots of women... Good times, bad times. The only thing I want anybody to say is: "he could really play. He was good»". Brown escucha y aprueba mientras ve Robert Johnson en Eugene; Hill tuvo aquí el acierto de reforzar la identificación con un plano casi gemelo del que veíamos en el proemio del film:
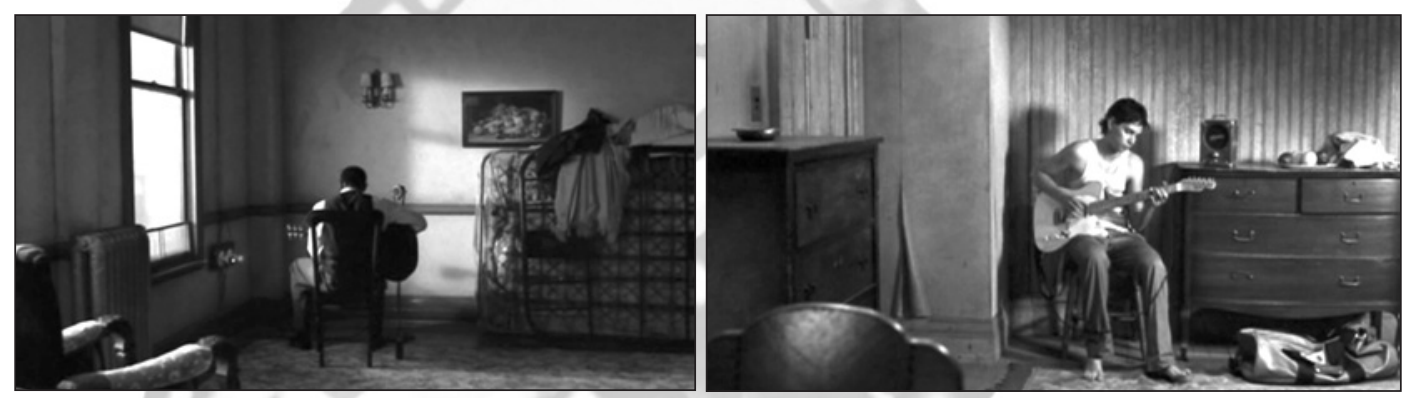

La única diferencia es que Johnson está de espaldas; por lo demás, ambos planos son casi idénticos: el mobiliario cochambroso y la luz, el punto de fuga en la esquina, el asiento a la izquierda... Tal vez Brown habla de Johnson, tal vez de sí mismo, o de Eugene; en este momento no importa, porque los tres se han fundido en el arquetipo del bluesman, en la leyenda de Johnson. Brown resume: "Blues ain't nothing but a man, feeling bad 'bout a woman".

Finalmente, para completar el ciclo Eugene debe hacer frente a la "prueba" final, el duelo con el agente del mal, que arruinó las almas de Johnson, Brown y tantos otros. El combate musical con que se cierra Crossroads es la parte más célebre del film, un lugar de culto para guitarristas de los 90 y los 2000 que acumula millones de visitas en Youtube. Con el episodio del bar como preludio, es el verdadero bautismo de fuego de Eugene. Eugene y Brown se han encontrado con Legba en el cruce, y pese a la oposición del viejo, acuerdan jugarse el 
alma de Brown en un combate musical: si Eugene pierde contra Butler (Steve Vai), el oscuro paladín del diablo, perderá también su alma.

Pero vence. Si los posicionamientos morales son, en este episodio, diáfanos, el mensaje acerca de la naturaleza del blues es algo confuso. El ataque con que Eugene vence a Butler, tras una demoledora demostración de blues eléctrico y moderno de este, consiste en un regreso a lo clásico: elabora un solo a partir del K 335 de Mozart y (aunque no aparece en los créditos finales) el capricho $n^{\circ} 5$ de Niccolo Paganini, sin perder del todo el tono del blues.

¿Se apela aquí a una concepción integradora de toda la música, a un camino de renovación para el blues? ¿Qué papel juega la referencia a Paganini? Es Eugene quien lo cita, pero es Butler quien lo remeda, visualmente. Paganini es, además, uno de los primeros músicos de quien se dijo que había vendido su alma al diablo a cambio de su destreza, y cuadra en muchos aspectos con el arquetipo del bluesman: bebedor, vagabundo, jugador — perdió un Stradivarius apostando a las cartas-, e irreverente (V. Martínez Estrada: 2001). Aquí se condensa esa confusión referencial que caracteriza al film, el uso indiscriminado de mitos, lugares comunes y referencias varias.

Aun así, la resolución del duelo puede tener un sentido interno coherente. Es claro que, de las características del bluesman de que Brown es defensor y depositario, Eugene solo ha tomado algunas, esencialmente las vivenciales —la sensación de diferencia, el vagabundeo, el enamoramiento...- y las musicales, dejando de lado las más violentas y oscuras. Así, si hay un mensaje explícito en Crossroads es el último consejo que Brown dirige a Eugene: "You gotta move on without me. Take the music someplace else. Take it past where you found it, because that's what we did". En él va implícita una propuesta que ya se venía fraguando, sotto voce, durante toda la cinta. Hill se inclina por considerar el blues como un discurso musical abierto, cambiante, una tradición abierta al otro. Eugene deviene un bluesman, pero un bluesman nuevo, un renovador de los viejos discursos que se ha formado en la tradición estricta del Delta y está listo para seguir por su propio pie. "After I show you Chigago you're by your own", le advierte Brown: es un final abierto de manual, en que ambos se alejan andando por un camino, y el color vira al sepia empleado en los flashbacks y los primeros planos de Johnson en el cruce.

\section{CROSSROADS O LOS DISCURSOS DEL BLUES}

En el cartel original de la película aparece, como reclamo, la frase "THE KID KEPTS THE LEGEND ALIVE...". Esto es verdad solo en parte, pues hay, como se ha visto, algo contradictorio en esta lectura del film. Gran parte de la película consiste en tantear el imaginario colectivo del blues y sus raíces primigenias, de forma más generalista que analítica, a través del mito de Johnson y de los arquetipos de Brown y Eugene. A través de éste se propone un tipo diferente de héroe, uno que, dada su juventud y manifiesta candidez, está aún libre de los rasgos más amorales del bluesman: la bebida, la violencia, el pillaje. En su triunfo frente a Butler y Legba se reafirma su condición de nuevo abanderado del blues, de arquetipo revisado; el chico blanco del norte que ha aprendido el lenguaje sonoro de los negros del sur desde el respeto y el trabajo. Hill resuelve la cuestión de la raza y la legitimidad del discurso del blues en los blancos con la misma sencillez que critica Rudinow (1997: 127-137), respondiendo a la burla que iniciaba Brown al inicio del film, para mortificación de Eugene: "This is rich... A bluesman from Long Island!". 
Recordar con insistencia un hecho no es revivirlo. El blues del Delta no fue solo un discurso musical e ideológico en un lugar, también lo fue en un momento. Como música, queda preservado en las grabaciones históricas y diseminado en los géneros que beben de él, como el rock o el soul. Como discurso de ideas, el blues tal vez quede, cada vez elucidado con una presunta mayor claridad, en los trabajos de los estudiosos. En el caso de Crossroads, el discurso propuesto es la celebración de una versión bien encarada de la memoria del blues y de la música en general. Esta mirada parte de una perspectiva poco consecuente con la realidad o con el interés por la realidad de lo que el blues fue, e imbuida de su tono laudatorio y su afán de agradar la película prefiere acogerse a la difusa tópica contemporánea del blues antes que indagar en busca de una reinterpretación propia. Tras lo dicho respecto al viaje iniciático de Eugene y el desarrollo argumental (planteamiento-nudo-desenlace con protagonistas y antagonistas) y moral de la cinta, se puede afirmar que Crossroads es, esencialmente, un cuento, amén de una película de culto para los músicos de las últimas generaciones.

Que represente el único acercamiento de la filmografía de Hill a los terrenos de la música también debe ser tenido en cuenta. Keith Negus ha hablado, siguiendo a Peterson, de la música country como de un "proceso en el que un conjunto de personas se dedica a la tarea irónicamente consciente de "fabricar autenticidad»" (Negus, 2005: 43). En Crossroads esto se traduce en una obvia voluntad por agradar al espectador y al melómano (V. Rothenbuhler: 2007). Según Negus, "los sonidos y significados musicales no sólo dependen de la manera en que la industria produce cultura, sino que también están condicionados por el modo en que la cultura produce una industria" (ibíd., 35). Así, los tópicos generados por un constructo cultural muy particular, como el blues rural de 1900 a 1930, pueden reorganizarse luego por sinergia, y esas reorganizaciones propician una industria que genera así una especie de dialéctica industria-cultura en la ecuación. La producción industrializada de cultura "no tiene lugar sólo dentro de un entorno empresarial estructurado [...], sino en relación con formaciones y prácticas culturales más amplias que se encuentran más allá del control de la compañía" (ibíd., 45).

No hay aquí una voluntad de exonerar a Crossroads de responsabilidades en tanto que producto cultural industrial; lo que interesa constatar es que la película es seguramente más un reflejo del contexto en que aparece que un agente del mismo, o en todo caso ambas cosas a un tiempo. En productos como este no sería del todo legítimo exigir una visión más fiel o auténtica de un universo conceptual que ni está claro ni, probablemente, se basa en una realidad efectiva, pero tal vez sí una mayor originalidad, un espíritu crítico que no se limite a condensar clichés para elaborar una pieza atractiva y sonora, pero parcialmente vacía y falaz.

\section{BIBLIOGRAFÍA}

HENDERSON, Stephen E., "The Blues as Black Poetry", Callaloo, n. 16 (Oct., 1982), pp. $22-$ 30.

HERZHAFT, Gérard, La gran enciclopedia del blues, Madrid, Ma non troppo, 2003.

JONES, LeRoi, Blues people. The Negro experience in white America and the music that developed from it., Nueva York, Morrow Quill Paperbacks, 1963.

KUBIK, Gerhard, Africa and the blues, Mississippi, UP of Mississippi, 1999.

MARCO, Tomás, Historia cultural de la música, Madrid, Ediciones Autor, 2008.

MARTÍNEZ ESTRADA, Ezequiel, Paganini, Rosario, Beatriz Viterbo Editora, 2001. 
NEGUS, Keith, Los géneros musicales y la cultura de masas, Barcelona, Paidós, 2005.

OTTENHEIMER, Harriet J., "Communication, and Evocation: Alternative Views of the Sociopsychological Functions of Blues", Ethnomusicology, vol. 23, n. 1, 1979, pp. 75-86.

ROTHENBUHLER, Eric W., "For-the-Record Aesthetics and Robert Johnson's Blues Style as a Product of Recorded Culture", Popular Music,Vol 26, n., 2007, pp. 65-81.

RUDINOW, Joel, "Race, Ethnicity, Expressive Authenticity: Can White People Sing the Blues?", Journal of Aesthetics and Art Criticism, vol. 52, n. 1, 1994, pp. 127-137.

SCHROEDER, Patricia R., Robert Johnson: Mythmaking and contemporary American culture, Illinois, University of Illinois, 2004.

SWITZLER, Robert, "Signifying the Blues", Alif: Journal of Comparative Poetics, n. 21, 2001, pp. 25-76.

TIRRO, Frank, Historia del jazz clásico, Barcelona, Ma non troppo, 2007.

WILD, Elijah, Escaping the Delta, Robert Johnson and the invention of the Blues, Nueva York, Harper Collins, 2006.

\section{Filmografía}

HILL, Walter, Crossroads, Columbia Pictures, 1986.

HUNT, Chris, The search for Robert Johnson, lambic Productions, 1992.

SCORSESE, Martin, Feel like going home, BBc \& Cappa Productions, 2003.

WENDERS, Win, The soul of a man, Cappa Productions et. al., 2003. 